\title{
The effect of head rotation on efficiency of ventilation and cuff pressure using the PLMA in pediatric patients
}

\author{
Hahck Soo Park, Jong In Han, and Youn Jin Kim \\ Department of Anesthesiology and Pain Medicine, School of Medicine, Ewha Womans University, Seoul, Korea
}

Background: This study examined whether changing the head position from neutral to side can affect expiratory tidal volume (TV) and cuff pressure when the appropriate sizes of a Proseal ${ }^{\mathrm{TM}}$ Laryngeal Mask Airway (PLMA) -depending on the body weight -are used in pediatric patients during pressure controlled ventilation (PCV).

Methods: Seventy-seven children $(5-30 \mathrm{~kg})$ were divided into three groups according to their body weight, PLMA\#1.5 (group I, $\mathrm{n}=24$ ), \#2 (group II, $\mathrm{n}=26$ ), and \#2.5 (group III, $\mathrm{n}=27$ ). After anesthesia induction, a PLMA was placed with a cuff-pressure of $60 \mathrm{cmH}_{2} \mathrm{O}$. The TV and existence of leakage at the peak inspiratory pressure (PIP) of 20 $\mathrm{cmH}_{2} \mathrm{O}$, and the appropriate PIP for TV $10 \mathrm{ml} / \mathrm{kg}$ were examined. Upon head rotation to the left side, the TV, PIP, cuff pressure changes, and the appropriate PIP to achieve a TV $10 \mathrm{ml} / \mathrm{kg}$ were evaluated.

Results: Head rotation of 45 degrees to the left side during PCV caused a significant increase in cuff pressure and a decrease in TV, and there was no definite leakage. Changes in PIP and TV were similar in the three groups. The cuff pressure increased but there was no significant difference between the three groups.

Conclusions: Although cuff pressure and TV of the PLMA were changed significantly after turning the head from the neutral position to the side, a re-adjustment of the cuff pressure and PIP to maintain a TV of $10 \mathrm{ml} / \mathrm{kg}$ can make the placed PLMA useful and successful in pediatric patients under general anesthesia. (Korean J Anesthesiol 2011; 61: 220-224)

Key Words: Head rotation, Pediatrics, PLMA.

Received: May 13, 2011. Revised: June 29, 2011. Accepted: July 12, 2011.

Corresponding author: Jong In Han, M.D., Ph.D., Department of Anesthesiology and Pain Medicine, School of Medicine, Ewha Womans University, 911, Mok-dong, Yangcheon-gu, Seoul 158-710, Korea. Tel: 82-2-2650-5559, Fax: 82-2-2655-2924, E-mail: hanji@ewha.ac.kr (c) This is an open-access article distributed under the terms of the Creative Commons Attribution Non-Commercial License (http:// creativecommons.org/licenses/by-nc/3.0/), which permits unrestricted non-commercial use, distribution, and reproduction in any medium, provided the original work is properly cited. 


\section{Introduction}

Proseal $^{\mathrm{TM}}$ Laryngeal Mask Airway (PLMA) is considered to be an effective and successful way to maintain the airway during general anesthesia in pediatric patients, although, in pediatric patients, airway closure is more likely to occur due to small vocal cords, relatively large tongue, and abundant lymphatic tissue around the airway [1]. Although PLMA placement in children has some advantages, such as a lower dose of muscle relaxant and easier intubation during general anesthesia due to the upper-front position of the larynx in children, it still has serious drawbacks. First, a failure of intubation or misplacement is more likely to occur because the vocal cord lies on the upper side of $\mathrm{C} 2-\mathrm{C} 4$ and the epiglottis is relatively long and stiff. Second, in the case of a misplacement of the PLMA, leakage can occur at the recommended air pressure, Third, although the appropriate sealing, tidal volume (TV), and peak inspiratory pressure (PIP) are maintained after successful placement of PLMA at the supine position, changes in the head position are frequently needed to avoid unwanted contact with surgeons caused by the confined space at the operation site as well as by airway, traction or position changes during surgery, such as myringotomy [2] or tympanostomy [3]. Anesthetized children have a narrowed upper airway [4] and are susceptible to collapse of the pharyngeal airway with head and neck rotation [5]. Although Choi and Kim [2] concluded that the efficacy of the seal for pediatric sized PLMAs are improved by head rotation for myringotomy, after head rotation to the side with PLMA, an adjustment of the cuff pressure and PIP can be urgently needed to get the appropriate TV and maintain effective ventilation in clinical settings.

Therefore, this study examined whether changing the head position from neutral to side during general anesthesia affects cuff pressure and ventilation efficiency when a suitable sized PLMA is used, one that is in accord with the body weight of the pediatric patient.

\section{Materials and Methods}

The study was approved by the appropriate Institutional Review Board. Pediatric patients from 6 months to 6 years old, who were scheduled to undergo surgery within 2 hours and met the following criteria, were enrolled in this study. The patients were classified as American Society of Anesthesiologists (ASA) physical status I or II without a previous airway infection or abnormality, and any head rotation during surgery while maintaining the supine position did not affect the procedures. Parents of patients consented to their children's participation in the study after they were given a detailed explanation about of the procedure of LMA placement for general anesthesia.
Before the induction of anesthesia, the age, body weight, height, and gender of the patients were recorded. Patients with a lesion on the neck or surrounding organs or those with a risk of lung aspiration including obese patients (BMI > 25) were excluded. Before induction of anesthesia, no medication was administered and parental presence was utilized before the patient's loss of consciousness. Vital signs, such as heart rate and blood pressure, electrocardiogram, and oxygen saturation level were recorded. To induce anesthesia, pentothal sodium (5 mg/kg), fentanyl ( $1 \mu \mathrm{g} / \mathrm{kg})$ and rocuronium $(0.6 \mathrm{mg} / \mathrm{kg})$ were injected after atropine $(0.02 \mathrm{mg} / \mathrm{kg}$, i.v.). After 2 minutes of mask ventilation with $4 \mathrm{~L} / \mathrm{min} \mathrm{O}_{2}$, an appropriately sized PLMA-depending on the body weight (PLMA \#1.5 for 5-10 $\mathrm{kg}$; \#2 for 10-20 kg; \#2.5 for 20-30 kg) - was inserted into the airway of the pediatric patients abiding by the manufacturer's instruction (ProSeal ${ }^{\mathrm{TM}}$ LMA, North America, Inc., San Diego, CA, USA). If the first trial failed, only one more trial was carried out after attempting mask-ventilation. If the additional trials failed, the patients were excluded from the study and endotracheal intubation was performed. A $3{ }^{\text {rd }}$ year resident who had performed PLMA insertion into pediatric patients under the age of 6 more than 20 times, placed the PLMA during the experiment. PLMA placement was performed using a standard method described by Brain [6]. Briefly, the patient's head was bent with the non-dominant hand, and the neck was extended. The PLMA was then inserted to the point of the triangular base in the center of the pharynx until the end of the PLMA reached the wall and some resistance was encountered. The cuff was inflated according to the manufacturer's instructions, and the cuff pressure was maintained at a constant $60 \mathrm{cmH}_{2} \mathrm{O}$ using a manometer (Mallinckrodt, Athlone, Ireland). Appropriate ventilation was confirmed by the auscultation of breathing sounds, the end-tidal $\mathrm{CO}_{2}$ curve and symmetric chest ventilation with smooth manipulation of a bag. To access the adequacy of the seal, a leak test was conducted with the head in the neutral position. The pop-off valve was closed with a gas flow rate of 3 $\mathrm{L} / \mathrm{min}$ and the airway pressure was allowed to increase until an air leak was audible at the mouth. The TV was then measured by checking for the existence of any leakage at PIP $20 \mathrm{cmH}_{2} \mathrm{O}$ during pressure controlled ventilation. To determine inspiratory pressure for $10 \mathrm{ml} / \mathrm{kg}$ of $\mathrm{TV}$, the addition or subtraction of 2 $\mathrm{cmH}_{2} \mathrm{O}$ of inspiratory pressure was performed, which was followed by an additional 5 min of maintenance after identifying the proper pressure point. After 5 minutes, we checked that the expiratory TV, cuff pressure, and existence of leakage had not changed. These values were recorded as baseline values.

In each patient, head and neck positions were changed using the following sequence: neutral and about $45^{\circ}$ rotation to the left side. Angle of head rotation was defined as the relative angle between the subject's sagittal plane and an imaginary line 
perpendicular to the floor, and was measured using a leveled protractor. The change in cuff pressure from $60 \mathrm{cmH}_{2} \mathrm{O}$, PIP and TV values, and existence of air leakage around the neck were measured again. The leakage after rotation was checked by readjusting the cuff pressure to $60 \mathrm{cmH}_{2} \mathrm{O}$. Change in PIP to achieve a TV of $10 \mathrm{ml} / \mathrm{kg}$ was determined with the addition or subtraction of $2 \mathrm{cmH}_{2} \mathrm{O}$ of inspiratory pressure and recorded. After these parameter were checked, the operation was started. The respiratory rate was regulated in order to maintain the endtidal $\mathrm{CO}_{2}$ at $30-35 \mathrm{mmHg}$, and anesthesia was maintained with an $\mathrm{O}_{2}$ :air mixture $(2: 2 \mathrm{~L} / \mathrm{min})$, and the level of sevoflurane was regulated at $2-3$ vol\% depending on the hemodynamic conditions during the operation.

When the operation was complete, the anesthetics were discontinued and the effect of the muscle relaxant was reversed by atropine and pyridostigmine under $100 \% \mathrm{O}_{2}$. After the recovery of spontaneous respiration and airway reflex, the PLMA was removed from the patients with the cuff inflated and the cuff volume was measured by deflation with a $30 \mathrm{ml}$-sized syringe.

Power analysis suggested that a minimum of 25 patients would be needed for $1-\beta=0.8, \alpha=0.05$. Twenty eight to thirty four patients were enrolled in each group in order to allow for any methodological difficulties that could lead to exclusion from the study. Statistical analyses were performed using the

Table 1. Demographic Data

\begin{tabular}{lccc}
\hline & $\begin{array}{c}\text { Group I } \\
\text { (PLMA\#1.5) } \\
(\mathrm{n}=24)\end{array}$ & $\begin{array}{c}\text { Group II } \\
(\text { PLMA\#2) } \\
(\mathrm{n}=26)\end{array}$ & $\begin{array}{c}\text { Group III } \\
(\text { PLMA\#2.5) } \\
(\mathrm{n}=27)\end{array}$ \\
\hline Age (yr)* & $0.8 \pm 0.2$ & $2.7 \pm 0.8$ & $4.4 \pm 2.3$ \\
Body weight (kg)* & $9.2 \pm 1.3$ & $14.6 \pm 4.1$ & $22.1 \pm 3.0$ \\
Sex (M/F) & $9 / 15$ & $14 / 12$ & $16 / 11$ \\
Anesthesia time (min) & $45.7 \pm 7.3$ & $48.1 \pm 10.2$ & $47.5 \pm 11.0$ \\
Type of surgery & $16 / 1 / 7$ & $19 / 2 / 5$ & $20 / 2 / 5$ \\
(GS/URO/OS) & & & \\
\hline
\end{tabular}

The data are reported as mean \pm SD or number of patients. GS: general surgery, URO: urologic surgery, OS: orthopedic surgery. ${ }^{*} \mathrm{P}<$ 0.05 among the three groups.
SPSS statistics program (version 12.0, SPSS Inc., USA), and all values are reported as mean $\pm \mathrm{SD}$. The changes in cuff pressure, TV and PIP to achieve a TV of $10 \mathrm{ml} / \mathrm{kg}$ after changing the head position from the neutral position to the side were compared using a Welch two sample t-test. Furthermore, multiple comparisons among the three groups were performed using Analysis of Variance (ANOVA). Non-changable parameters, such as gender and surgery type, were compared using a Kruskal-Wallis test. $P$ values $<0.05$ were considered significant.

\section{Results}

There was a significant difference in age and body weight, as expected, but the other parameters, such as gender, anesthesia time and surgery types were similar among the three groups (Table 1). The number of patients excluded from data analyses due to a failure of PLMA insertion was 5, 2, and 7 from groups I, II, and III, respectively. Therefore, a total of 77 of 91 pediatric patients participated in this study (Proseal ${ }^{\mathrm{TM}}$ LMA \# 1.5 (group I, $\mathrm{n}=24$ ), \#2 (group II, $\mathrm{n}=26$ ), and \#2.5 (group III, $\mathrm{n}=27$ )). Shortly after inserting the PLMA, the TV measured at a PIP of $20 \mathrm{mmHg}$ in groups I, II, and III was $177.3 \pm 31.4,318.4 \pm 104.8$, and 330.4 $\pm 121.6 \mathrm{ml}$, respectively. Air leakage occurred in one patient in group III, but secure sealing without leakage was achieved after the second trial of PLMA insertion. The values of PIP at a $\mathrm{TV}$ of $10 \mathrm{ml} / \mathrm{kg}$ in groups I, II, and III were $12.2 \pm 1.4,12.2 \pm 2.5$, and $13.4 \pm 3.7 \mathrm{cmH}_{2} \mathrm{O}$, respectively. There were no significant differences among the values of PIP of the three groups. In case of head rotation from neutral to side, the changes in cuff pressure in groups I, II and III were $7.2 \pm 5.0,11.2 \pm 13.8$, and $11.9 \pm 7.4 \mathrm{cmH}_{2} \mathrm{O}$, respectively, but there was no significant difference among the three groups. After head rotation to the side, the changes in TV measured during expiration in groups I, II and III were $-27.1 \pm 21.5,-38.7 \pm 43.8$ and $-62.2 \pm 28.0 \mathrm{ml}$, respectively. Although these values seem to be significant, the converted percentages were similar in the three groups $(-29 \%$, $-26.5 \%,-26.7 \%)$. PIP values to compensate for the reduced TV

Table 2. Comparison of the Data Obtained Upon Head Rotation

\begin{tabular}{|c|c|c|c|c|c|c|}
\hline & $\begin{array}{l}\text { TV-PIP20 } \\
(\mathrm{ml} / \mathrm{kg})\end{array}$ & $\begin{array}{l}\text { PIP-TV10 } \\
\left(\mathrm{cmH}_{2} \mathrm{O}\right)\end{array}$ & $\begin{array}{c}\text { TV-change (ml) } \\
(\%)\end{array}$ & $\begin{array}{l}\text { PIP-TV10 rotation } \\
\quad\left(\mathrm{cmH}_{2} \mathrm{O}\right)\end{array}$ & $\begin{array}{l}\text { Cuff-pr. change } \\
\quad\left(\mathrm{cmH}_{2} \mathrm{O}\right)\end{array}$ & $\begin{array}{l}\text { cuff-vol. in } \\
\text { rotation }(\mathrm{ml})\end{array}$ \\
\hline $\begin{array}{l}\text { Group I } \\
\text { (PLMA\#1.5) }\end{array}$ & $19.3 \pm 3.4$ & $12.1 \pm 1.4$ & $\begin{array}{c}-27.1 \pm 21.5^{*} \\
(-29.0 \%)\end{array}$ & $14.0 \pm 1.8^{*}$ & $7.2 \pm 5.0^{*}$ & $4.9 \pm 0.4^{\dagger}$ \\
\hline $\begin{array}{l}\text { Group II } \\
\text { (PLMA\#2) }\end{array}$ & $21.7 \pm 7.2$ & $12.2 \pm 2.5$ & $\begin{array}{c}-38.7 \pm 43.8^{*} \\
(-26.5 \%)\end{array}$ & $13.5 \pm 2.0^{*}$ & $11.2 \pm 13.8^{*}$ & $7.0 \pm 0.7^{\dagger}$ \\
\hline $\begin{array}{l}\text { Group III } \\
\text { (PLMA\#2.5) }\end{array}$ & $14.5 \pm 5.3$ & $13.4 \pm 3.7$ & $\begin{array}{c}-61.2 \pm 28.0^{*} \\
(-26.7 \%)\end{array}$ & $16.0 \pm 3.6^{*}$ & $11.9 \pm 7.4^{*}$ & $10.4 \pm 1.5^{\dagger}$ \\
\hline
\end{tabular}

The data are reported as mean \pm SD. TV-PIP20: tidal volume at $20 \mathrm{cmH}_{2} \mathrm{O}$ peak inspiratory pressure, PIP-TV10: peak inspiratory pressure at 10 $\mathrm{ml} / \mathrm{kg}$ tidal volume, TV change: tidal volume change after head rotation, PIP-TV10 rotation: inspiratory pressure at $10 \mathrm{ml} / \mathrm{kg}$ tidal volume after head rotation, Cuff-pr. Change: LMA cuff pressure change after head rotation, cuff-vol.in rotation: LMA cuff volume after removal. $* \mathrm{P}<0.05$ between the two positions, ${ }^{\dagger} \mathrm{P}<0.05$ among thethree groups. 
to $10 \mathrm{ml} / \mathrm{kg}$ in groups I, II and III were $14.0 \pm 1.8,13.5 \pm 2.0$, and $16.0 \pm 3.6 \mathrm{cmH}_{2} \mathrm{O}$, respectively. These values were significantly different compared to the values at neutral position, and there were no statistical differences among the three groups. Upon recovery from anesthesia, the cuff volumes of the removed PLMA in groups I, II and III were $4.9 \pm 0.4,7.0 \pm 0.7$ and $10.4 \pm 1.5$ $\mathrm{ml}$, respectively, and the volumes were significantly different (Table 2). Two patients from group II complained of hoarseness after surgery.

\section{Discussion}

This study examined the effect of 45 degree head rotation from a neutral position to head rotation to the side position with PLMA placement on several respiratory parameters such as TV and PIP, and changes in cuff pressure, in pediatric patients who were scheduled to undergo surgery within 2 hours under pressure-controlled ventilation (PCV). These parameters changed significantly upon head rotation to the left side and needed to be re-adjusted to maintain proper respiration. Although the increase in PIP, decrease in TV and increase in cuff pressure were significant as a function of head rotation, the changes in these values were not significant clinically because it can be safely sustained without any problem with the head rotation to side if the PLMA is placed correctly at the supine position. The time taken to re-adjust to proper respiration after head rotation was dependent on the extent of how secure the PLMA placement had been in the neutral position. Our results are consistent with the study of Choi and Kim [2]. They reported the influence of head rotation on the PLMA airway sealing during pediatric myringotomy, and supported the hypothesis that head rotation is associated with a stable patent airway with no detrimental effects [2]. Keller and Brimacombe [7] examined the effect of head and neck position on oropharyngeal leak pressure (OLP) and cuff position fiberoptically. They reported that flexion and extension, not rotation, affected OLP significantly. Isserles and Rozenberg reported that if extension was avoided, the head rotation did not affect leak pressure and PLMA score [8].

Increased cuff volume and cuff pressures have been shown to result in increased incidence of trauma to the laryngeal and pharyngeal structures [9-11]. Cuff pressure depends on the PLMA size, cuff volume and patient's position. The cuff pressure of a smaller PLMA is higher than that of a larger LMA, when the cuffs were insufflated with the maximum recommended PLMA filling volume [12]. Yano et al. [13] reported that if the same cuff volume was injected into different body positions, the cuff pressure was higher in the supine position than in the lateral position, and this difference is caused by the upper airway tract widening due to gravity. Maino et al. [12] reported a maximum recommended PLMA filling volumes of $7 \mathrm{ml}$ (\#1.5), $10 \mathrm{ml}$ (\#2), $14 \mathrm{ml}$ (\#2.5) and $20 \mathrm{ml}$ (\#3). Our final cuff volumes were 4.9 $\mathrm{ml}$ (\#1.5), $7.0 \mathrm{ml}$ (\#2), and $10.4 \mathrm{ml}$ (\#2.5) after head rotation to the side. These are smaller volumes than the maximum recommended filling volumes without any leakage, if we reduced the increased cuff pressure with head rotation to the generally recommended optimal closure pressure $\left(60 \mathrm{cmH}_{2} \mathrm{O}\right)$. The hyperinflation of the cuff not only results in an increased risk for pressure-related morbidity, but also significantly impairs cuff sealing [14]. Therefore, it is recommended to use a cuff pressure at which leakage does not occur.

The cuff pressure maintaining TV at $10 \mathrm{ml} / \mathrm{kg}$ at the neutral position increased with head rotation according to the PLMA size (7.2, 11.2 and $11.9 \mathrm{cmH}_{2} \mathrm{O}$ in groups I, II, and III, respectively), but there were no significant differences among the three groups. These results might be due to the fact that the space occupied by the PLMA in the oropharynx added some pressure to the air sac due to a contraction of the lengthwise diameter of the airway upon head rotation. Licina et al. [14] reported that the continuous maintenance of $60 \mathrm{mmH}_{2} \mathrm{O}$ rather than an increase in cuff pressure can maintain an effective seal, and we readjusted the cuff volume to maintain a fixed cuff pressure upon head rotation. The decreases in TV were similar, irrespective of the PLMA size $(-29.0,-26.5$, and $-26.7 \%$, for groups I, II, and III, respectively), and an increase in PIP to compensate for the decrease in TV is required $\left(14.0,13.5\right.$, and $16.0 \mathrm{cmH}_{2} \mathrm{O}$, for groups I, II, and III, respectively). Two patients complained of hoarseness after PLMA placement but there was no close correlation with the surgery type, anesthesia time or cuff volume. One patient from group II experienced postoperative vomiting after a hernia operation, which might have been caused by gastric distention and gas leakage. Therefore, further studied, such as standardization and comparison of a change in abdomen circumference before and after PLMA placement, and its association with postoperative vomiting, are warranted.

Although the oropharyngeal leak pressure for the size 2 PLMA is higher than the classic LMA (23.7 vs $16.5 \mathrm{cmH}_{2} \mathrm{O}$ ), the occurrence of a gas leak during positive pressure ventilation depends on the interplay of several factors such as fresh gas flow, pharyngeal tone, head position and respiratory system compliance [15]. With the classic LMA (cLMA), positive pressure ventilation in pediatric patients can be difficult or even impossible when the required peak inspiratory pressure is higher than the leak pressure obtained with the cLMA in that patient [16]. In our study, inspiratory leak and gastric insufflations didn't change after head rotation because every patients had $10 \mathrm{ml} / \mathrm{kg}$ TV below $20 \mathrm{cmH}_{2} \mathrm{O}$ PIP in the supine position and head rotation position. The importance of gas leaks was correlated with the PIP: the higher the PIP, the greater the risk of gastric insufflations [17]. The risk is also increased if the 
LMA is malpositioned [18]. Wahlen et al. [18] concluded that clinically undetected LMA malpositioning is a significant risk factor for gastric air insufflation in children between 3 and 11 years, undergoing positive pressure ventilation, especially at inspiratory airway pressures above $17 \mathrm{cmH}_{2} \mathrm{O}$. In this aspect, the lower pressure obtained with pressure-controlled ventilation (PCV) might reduce the risk of gastric insufflations [19]. Bordes et al. [20] suggested that PCV is more efficient than VCV for controlled ventilation with a laryngeal mask in children.

The PLMA is an LMA device designed to improve the quality of positive pressure ventilation [21]. Its efficacy in providing good conditions for PPV has been demonstrated in children [22-24]. The improved seal, compared with the classic LMA, with pediatric sizes $(1.5,2,2.5)$, which lack a dorsal cuff, is likely because of a better anatomic fit in the pharynx of the PLMA cuff compared with the classic LMA [25]. Hence, our study also used PLMA; in cases where e PLMA was safely placed in the supine position, it was observed that even with head rotating, the PLMA maintained a safe placement.

This study was performed in a patient group scheduled to undergo surgery in the supine position. Head rotation was allowed in order to examine its effects on two respiratory parameters. However, further study will be needed to examine those parameters separately in the supine and head rotation positions. In addition, a fiberoptic bronchoscope might be useful for checking the position of the PLMA in the supine and head rotation positions. The one limitation of this research could be that a fiberscopic examination was not conducted.

In conclusion, PLMA placement is useful for stable ventilation in pediatric patients in both the neutral position and after head rotation to the side. It is safe after head rotation if the PIP is increased to maintain the required TV and the cuff volume is reduced to achieve a tight seal.

\section{References}

1. Son SC, Ko YK, Lee SJ. Comparison of ETT and LMA on respiratory mechanics during the induction of general anesthesia in children. Korean J Anesthesiol 2004; 47: 772-8.

2. Choi WJ, Kim YH. The influence of head rotation on ProSeal laryngeal mask airway sealing during paediatric myringotomy. Anaesth Intensive Care 2007; 35: 957-60.

3. Hoffmann KK, Thompson GK, Burke BL, Derkay CS. Anesthetic complications of tympanostomy tube placement in children. Arch Otolaryngol Head Neck Surg 2002; 128: 1040-3.

4. Evans RG, Crawford MW, Noseworthy MD, Yoo SJ. Effect of increasing depth of propofol anesthesia on upper airway configuration in children. Anesthesiology 2003; 99: 596-602.

5. Ishikawa T, Isono S, Aiba J, Tanaka A, Nishino T. Prone position increases collapsibility of the passive pharynx in infants and small children. Am J Respir Crit Care Med 2002; 166: 760-4.

6. Brain AI. The laryngeal mask - a new concept in airway manage- ment. Br J Anaesth 1983; 55: 801-5.

7. Keller C, Brimacombe J. The influence of head and neck position on oropharyngeal leak pressure and cuff position with the flexible and the standard laryngeal mask airway. Anesth Analg 1999; 88: 913-6.

8. Isserles SA, Rozenberg B. LMA--reduction of gas leak. Can J Anaesth 1995; $42: 449$.

9. Inomata S, Nishikawa T, Suga A, Yamashita S. Transient bilateral vocal cord paralysis after insertion of a laryngeal mask airway. Anesthesiology 1995; 82: 787-8.

10. Lloyd Jones FR, Hegab A. Case report. Recurrent laryngeal nerve palsy after laryngeal mask airway insertion. Anaesthesia 1996; 51: 171-2.

11. Martins RH, Braz JR, Defaveri J, Gregório EA, Abud TM. Effect of high laryngeal mask airway intracuff pressure on the laryngopharyngeal mucosa of dogs. Laryngoscope 2000; 110: 645-50.

12. Maino P, Dullenkopf A, Keller C, Bernet-Buettiker V, Weiss M. Cuff filling volumes and pressures in pediatric laryngeal mask airways. Paediatr Anaesth 2006; 16: 25-30.

13. Yano T, Imazumi T, Uneda C, Nakayama R. Lower intracuff pressure of LMA in the lateral and prone positions compared with that in the supine position. J Anesth 2008; 22: 312-6.

14. Licina A, Chambers NA, Hullett B, Erb TO, von Ungern-Sternberg BS. Lower cuff pressures improve the seal of pediatric laryngeal mask airways. Pediatr Anaesth 2008; 18: 952-6.

15. Lardner DR, Cox RG, Ewen A, Dickinson D. Comparison of laryngeal mask airway (LMA)- Proseal and the LMA-Classic in ventilated children receiving neuromuscular blockade. Can J Anaesth 2008; 55: 29-35.

16. Ramachandran SK. Positive pressure ventilation with the LMA: inspiratory leaks and effect on the adequacy of ventilation. Acta Anaesthesiol Scand 2007; 51: 778.

17. Ho-Tai LM, Devitt JH, Noel AG, O'Donnell MP. Gas leak and gastric insufflations during controlled ventilation: face mask versus laryngeal mask airway. Can J Anaesth 1998; 45: 206-11.

18. Wahlen BM, Heinrichs W, Latorre F. Gastric insufflation pressure, air leakage and respiratory mechanics in the use of the laryngeal mask airway (LMA) in children. Paediatr Anaesth 2004; 14: 313-7.

19. Keidan I, Berkenstadt H, Segal E, Perel A. Pressure versus volumecontrolled ventilation with a laryngeal mask airway in paediatric patients. Paediatr Anaesth 2001; 11: 691-4.

20. Bordes M, Semjen F, Degryse C, Bourgain JL, Cros AM. Pressurecontrolled ventilation is superior to volume-controlled ventilation with a laryngeal mask airway in children. Acta Anaesthesiol Scand 2007; 51: 82-5.

21. Brain AI, Verghese C, Strube PJ. The LMA 'ProSeal'--a laryngeal mask with an oesophageal vent. Br J Anaesth 2000; 84: 650-4.

22. Goldmann K, Jakob C. Size 2 ProSeal laryngeal mask airway: a randomized, crossover investigation with the standard laryngeal mask airway in paediatric patients. Br J Anaesth 2005; 94: 385-9.

23. Lopez-Gil M, Brimacombe J. The ProSeal laryngeal mask airway in children. Paediatr Anaesth 2005; 15: 229-34.

24. Wheeler M. ProSeal laryngeal mask airway in 120 pediatric surgical patients: a prospective evaluation of characteristics and performance. Paediatr Anaesth 2006 ; 16: 297-301.

25. Sanders JC, Olomu PN, Furman JR. Detection, frequency and prediction of problems in the use of the proseal laryngeal mask airway in children. Paediatr Anaesth 2008; 18: 1183-9. 